\title{
Pesquisador brasileiro desenvolve métodos de ensaios promissores para diagnóstico de reações expansivas no concreto
}

FÁBIO LUÍS PEDROSO - EDITOR

$\Lambda$ $\mathrm{S}$ estruturas de concreto podem, sob certas condições, sofrer deterioração com reações expansivas entre os componentes em seu interior. A reação álcali-agregado (RAA) foi detectada há mais de 70 anos, sendo uma reação química entre as sílicas reativas dos agregados e os álcalis do cimento, solúveis nos poros do concreto. A reação forma um gel, que, na presença de água, expande-se, provocando tensões internas nas peças de concreto, ocasionando sua fissuração.

Já, a etringita tardia ou secundária (DEF, do inglês "Delay Etringgite Formation") veio a ser conhecida apenas na

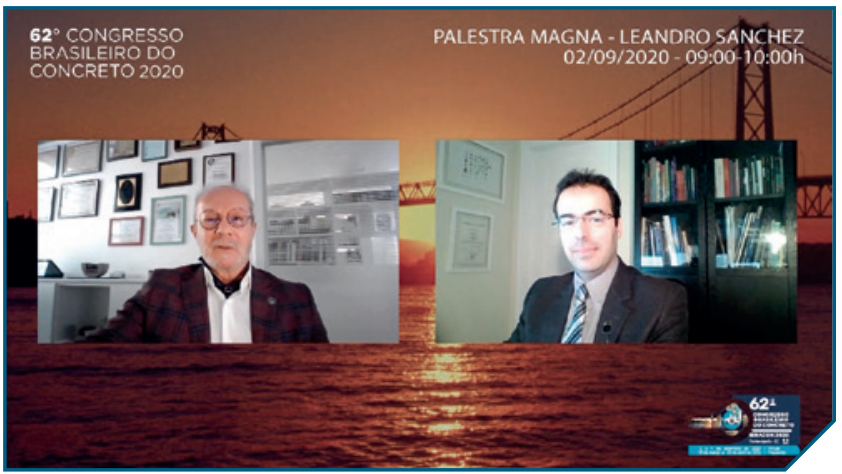

Figura I - O presidente do IBRACON, Prof. Paulo Helene, apresenta o Prof. Leandro Sanchez, na abertura de sua palestra magna no 62॰ CBC 2020 década de 1980. A etringita primária é um dos primeiros produtos decorrentes da hidratação do cimento, ou seja, a reação química entre o cimento e a água que leva ao endurecimento do concreto, sendo, portanto, normal no concreto fresco e sem causar problemas futuros. Porém, quando a temperatura do concreto nas primeiras idades supera valores da ordem de 60 a 70 graus Celsius, pode haver uma desestabilização desse produto e ocorrer o desencadeamento de uma nova reação expansiva, agora muito deletéria porque o concreto já está endurecido e vai fissurar.

Os cientistas têm estudado os fenômenos de reações expansivas no concreto e lançado mão de estratégias teóricas e práticas para estimar as origens, a extensão e a evolução da deterioração de peças de concreto afetadas pela RAA e DEF. "Saber o mecanismo de origem da expansão na peça de concreto, seu grau de deterioração e com que velocidade está se expandindo é imprescindível para saber quais soluções de engenharia usar para minimizar a expansão e estender a vida útil da estrutura", contextualizou o professor da Universidade de Ottawa, no Canadá, Leandro Sanchez, em sua palestra magna no $62^{\circ}$ Congresso Brasileiro do Concreto (Fig. 1).

O Prof. Leandro Sanchez trouxe as investigações que vem desenvolvendo com sua equipe em termos de ensaios de laboratório para diagnóstico das reações expansivas no concreto e de modelos matemáticos para previsão da evolução dessa expansão no tempo.

Ele apresentou o método de análise visual, que consiste em usar epóxi fluorescente na amostra fissurada por RAA. Sob luz ultravioleta, o epóxi fluorescente brilha, possibilitando localizar e quantificar as fissuras, medir seu comprimento, profundidade e densidade na amostra, por meio de fotografias em escala microscópica. Essa quantificação e localização das fissuras com uso de softwares 
possibilitam conhecer a causa e a extensão dos mecanismos de expansão.

Segundo Leandro Sanchez, um método de ensaio microscópico promissor é o "Damage Rating Index" (DRI), que consiste em localizar, quantificar e medir, por meio de uma lupa binocular com aumento de 16 vezes, as fissuras por centímetro quadrado num testemunho de concreto, multiplicando esses índices por fatores de ponderação relacionados ao local e características dessas fissuras, para chegar no índice geral de deterioração da peça (DRI). Segundo Sanchez, o DRI tem se mostrado pertinente para diagnosticar RAA e DEF, uma vez que o índice aumenta proporcionalmente com o aumento da expansão da peça deteriorada, independentemente do tipo de agregado usado no concreto e de suas propriedades mecânicas.

Esse método tem sido automatizado com o uso da chamada inteligência artificial na Universidade de Ottawa, para possibilitar diagnósticos rápidos do tipo de reação expansiva, nível de expansão e de perda das propriedades mecânicas do concreto estrutural. $\mathrm{O}$ procedimento consiste em criar um banco de imagens com DRI feito por um ser humano, que sirva de base para o aprendizado da máquina, de forma a automatizar o ensaio, que é demorado. "Com um banco atual de mais de 2000 imagens, a inteligência artificial associada ao DRI tem obtido um grau de $85 \%$ de precisão no diagnóstico de RAA e DEF. Nossa previsão é conseguirmos calcular o DRI automaticamente em quatro anos", complementou Sanchez. É interessante salientar que a RAA e a DEF, apesar de fenômenos físico-químicos distintos, têm feições sintomatológicas bastante similares à

primeira vista, o que pode levar a erros nos diagnósticos.

Segundo Sanchez, acoplados aos ensaios visuais, os ensaios mecânicos possibilitam avaliar a extensão da deterioração. Isto porque a deterioração é formada pela redução da integridade física (durabilidade), da rigidez e das propriedades mecânicas da estrutura de concreto.

O ensaio de tração possibilita avaliar a quantidade e a abertura das fissuras. A amostra fissurada é fechada hermeticamente numa caixa, com gás sob pressão, que, penetrando nas fissuras, rompe a amostra por tração. O ensaio à tração por pressão está sendo estudado na Universida-

de de Ottawa como instrumento promissor para diagnósticos das reações expansivas no concreto, uma vez que tem mostrado boa correlação com o ensaio de tração direta, sem apresentar

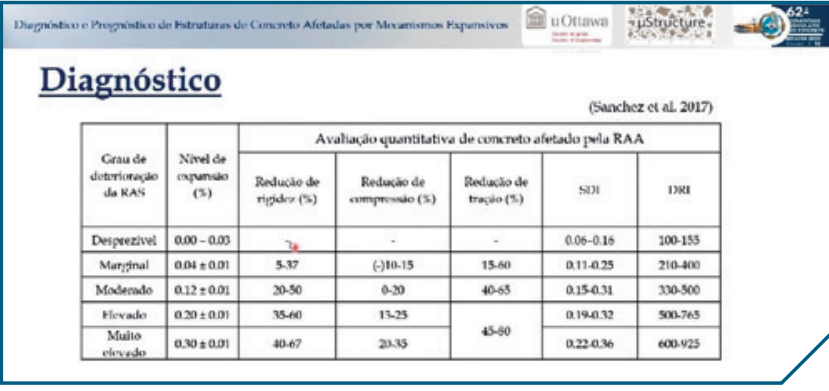

Figura 2 - Slide apresentado pelo Prof. Leandro Sanchez em sua palestra magna suas limitações, como a excentricidade da amostra e a ruptura na cola do corpo de prova, que distorcem os resultados.

○ ensaio de compressão modificado ("Stiffness Damage Test" - SDT) consiste em executar cinco ciclos de compressão de uma amostra, com uma carga $40 \%$ da carga total de ruptura do testemunho extraído, fazendo suas fissuras fecharem e plastificarem, de modo a gerar uma curva de tensão x deformação, cujas áreas são medidas. $\mathrm{O}$ ensaio tem mostrado resultados com correlação positiva com o nível de expansão por RAA e DEF, independentemente dos tipos de agregados e das propriedades mecânicas do concreto.

A fissuração dentro dos agrega- dos, em razão das reações expansivas, causa perda do 'engrenamento' dos agregados no concreto, o que pode ser detectado pelo ensaio de cisalhamento, cujos resultados têm também mostrado correlação com a expansão ocasionada pela RAA e DEF.

A combinação dos estudos com os ensaios visuais e mecânicos engendrou uma avaliação multinível que possibilita correlacionar os resultados dos ensaios com o nível e expansão da fissuração da estrutura ensaiada e com as perdas de suas propriedades mecânicas (Fig. 2). "Nosso grupo de pesquisa tem desenvolvido as pesquisas com a cria- 